\title{
AVALIAÇÃO DAS PERDAS DE MANGA NO MERCADO VAREJISTA DO VALE DO SÃO FRANCISCO
}

\author{
Wendell Ramon Barbosa Machado* \\ Rodrigo Mendes de Carvalho** \\ Acácio Figueiredo Neto***
}

RESUMO: O atual trabalho teve como alvo realizar levantamento das perdas das variedades de manga no mercado varejista da região do Vale do São Francisco, bem como suas causas e providências a serem tomadas. Para tal análise, foram feitas pesquisas, visitações e aplicação de entrevistas nos canais varejistas (supermercado, hortifrúti e feira livre). Os resultados evidenciaram que a perda de manga, semanalmente, corresponde em média 14\% da variedade Tommy Atkins, $7 \%$ da Rosa, $12 \%$ da variedade Palmer, $17 \%$ da Espada e $14 \%$ de outras variedades encontradas (Keit, Kent e Handen). Os hortifrútis, por serem os principais mercados varejistas, são predominantes também como o canal que mais perde $(15,88 \%$ das suas variedades de manga adquiridas). Os canais varejistas referiram-se diferentemente dos principais causadores de perdas de manga. Para os supermercados e as feiras livres foi identificada a excessiva manipulação do fruto por parte do cliente como o principal causador de perda (33,33\% para os supermercados e $46,43 \%$ para as feiras). Já para os hortifrútis, a rápida maturação da fruta foi a principal causa, cerca de $58,62 \%$. O controle de compra, a educação dos clientes e a melhoria dos locais de armazenamento são ajustes prioritários a serem tomados conforme cada rede varejista. Sendo assim, considera-se que a os canais mais tradicionais da região do Vale do São Francisco necessitam desenvolver melhor sua distribuição de manga para os clientes, a fim de reduzir as perdas de qualidade e também monetárias.

PALAVRA-CHAVE: Manga; Mercado; Perdas; Varejo.

\section{ASSESSMENT OF MANGO LOSSES ON THE WHOLESALE MARKET OF THE VALE DO SÃO FRANCISCO, BRAZIL}

ABSTRACT: Losses in mango varieties on the wholesale market of the Vale do

Graduando em Engenharia de Produção pela Universidade Federal do Vale do São Francisco (UNIVASF), Brasil.

** Graduando em Engenharia de Produção pela Universidade Federal do Vale do São Francisco (UNIVASF), Brasil.

**** Docente Adjunto da Universidade Federal do Vale do São Francisco (UNIVASF), Brasil.

E-mail: acacio.figueiredo@univasf.edu.br 
São Francisco, Brazil, their causes and precautions for avoidance are investigated. Research, visits and interviews have been undertaken in wholesale markets (supermarkets, fruit and vegetable markets and fairs) for current analysis. Results shows that mango weekly losses average $14 \%$ for Tommy Atkins variety, $7 \%$ for Rosa variety, $12 \%$ for Palmer variety, $17 \%$ for Espada variety and 14\% for other varieties (Keit, Kent and Handen). The fruit and vegetable market, the main wholesale market, has the greatest losses, with $15.88 \%$ of mango varieties. Wholesalers attributed mango losses to different causes. Whereas managers of supermarkets and fairs identified excessive handling of the fruit by the client as the main cause of losses $(33.33 \%$ in the case of supermarkets and $46.43 \%$ in the case of fairs), the vegetable and fruit markets attributed losses to fast fruit maturation (58.62\%). Buying control, clients' behavior and storing improvement should take first place. The more traditional fruit outlets of the Vale do São Francisco region should develop better mango distribution to clients so that quality and financial liabilities would be avoided.

KEY WORD: Mango; Market; Losses; Wholesale.

\section{INTRODUÇÃO}

O Brasil utilizou em 2013 cerca de 2,2 milhões de hectares para a produção de frutas (SEBRAE, 2015). O Nordeste consta do ranking das principais regiões brasileiras produtoras de frutas. De acordo com o Anuário Brasileiro de Fruticultura (2016), a Bahia possuía em 2014 uma produção de frutas de 4.058 .678 toneladas, $2^{\mathrm{a}}$ maior do país, sendo $1.088 .647 \mathrm{t}$ para a banana, $1.026 .167 \mathrm{t}$ para laranja, mamão correspondendo a 794.565 t, manga 430.594 t e maracujá 381.192 t. Ainda segundo o mesmo documento o Estado de Pernambuco possuía em 2014 uma produção de 975.010 toneladas, $7^{\mathrm{a}}$ maior, das quais $40,66 \%$ correspondem à banana, 24,22\% para a uva, 22,43\% para a manga e 12,69\% correspondendo às demais variedades de frutas produzidas.

Assim, o Vale do São Francisco, região a qual engloba algumas cidades desses dois Estados, é conhecido como a região mais próspera do interior nordestino, que se encontra totalmente na zona semiárida do Nordeste brasileiro.

Em 2015 a produção brasileira de frutas frescas foi cerca de 40,6 milhões de toneladas, dos quais 1,13 milhões correspondem a manga (ANUÁRIO BRASILEIRO DE FRUTICULTURA, 2016). 
A manga é uma fruta nativa da Ásia, mais precisamente da Índia. Conforme Castro Neto e Cunha (2000), a manga tem uma importância econômica, promovida pelo seu excelente sabor e boas condições nutritivas e também é a sétima cultura mais plantada no mundo e a terceira mais cultivada nas regiões tropicais, em aproximadamente 94 países. De acordo com Pinto, Matos e Cunha (2000), as variedades mais aconselhadas para o consumo são as que oferecem alta produtividade, coloração atraente do fruto (de preferência vermelha), polpa doce $\left(17^{\circ}\right.$ Brix) e pouca ou nenhuma fibra, além da resistência ao manuseio e ao transporte para mercados distantes. Eles ainda afirmam que as variedades Tommy Atkins, Keitt, Kent, Van Dyke e Palmer são as principais variedades-copa cultivadas para consumo in natura.

Em 2015, de acordo com o Anuário Brasileiro de Fruticultura (2016), o Brasil exportou 156 mil toneladas de manga, dos quais 84\% (cerca de 131,5 mil) foram do Vale do São Francisco. O restante da produção ficou retido no país, seguindo os mais diversos caminhos. Parte da produção é direcionada ao consumo in natura, outra parte vai para a fabricação de derivados como o doce, polpa e geleia de manga. Mesmo com o desenvolvimento da fruticultura, os brasileiros ainda não consomem a quantidade de frutas recomendada pela Organização Mundial da Saúde (OMS), o que revela um mercado em potencial para o setor. SEBRAE (2015) afirma que em termos gerais, o consumo médio no país é de $33 \mathrm{~kg}$ por habitante ao ano, muito abaixo do recomendado, de $100 \mathrm{~kg}$ por habitante ao ano.

Atualmente, só no Brasil, de acordo com Banco de Alimentos (2016), 26,3 milhões de toneladas de alimentos têm o lixo como o seu destino, sendo a maior perda (45\%) de hortaliças e de frutas, isso se dá devido à sensibilidade dos produtos às condições do ambiente em que eles estão presentes.

No Brasil, 35\% de toda produção agrícola é desperdiçada antes do consumo; $10 \%$ ocorre ainda na colheita; $50 \%$ ocorre no manuseio e transporte; $30 \%$ ocorre nas centrais de abastecimento e $10 \%$ são diluídos entre supermercados e consumidores (IPEA, 2009). Como um dos principais locais de comercialização das frutas, o mercado varejista, conforme Trento, Sepulcri e Morimoto (2011), é composto pelos canais tradicionais como as feiras livres, os varejões, as quitandas, as mercearias, os ambulantes, sacolões, mercados municipais e os canais que englobam as grandes redes de supermercados. 
Tofanelli et al. (2007) constataram que no mercado varejista de Mineiros (GO) houve uma perda de 3,2\% do volume de frutas comercializado e que os supermercados, por serem os principais mercados varejistas, são predominantes no volume de perdas. Já Pedrosa et al. (2009) verificaram o número de perdas das variedades de manga no mercado varejista da cidade de Botucatu (SP), foi averiguado que as perdas médias por variedade de manga foram de 11,5\% para Tommy Atkins, $12,4 \%$ para Haden e $12,7 \%$ para as outras variedades.

As perdas na comercialização da manga podem ser de ordem quantitativa, ou seja, redução na quantidade física do produto disponível para o consumo; qualitativa, que é a diminuição na qualidade da fruta; e nutricional. Essas perdas geram grandes prejuízos econômicos, notadamente porque inviabilizam a comercialização de alguns frutos e diminuem o valor comercial de outros (CHOUDHURY; COSTA, 2004).

Segundo Perosa et al. (2009), ainda que as causas das perdas não estejam associadas exclusivamente ao varejo, a determinação das mesmas nessa etapa da comercialização pode dar subsídios aos atuantes da cadeia agroalimentar da manga, encaminhando-os para ações que melhorem a cadeia de comercialização desta fruta.

O conceito de perda, neste trabalho, baseia-se em Vilela, Lana e Makishima (2003), que definem como a parte física da produção que não é destinada ao consumo, em razão de depreciação da qualidade dos produtos, devido à deterioração, causada por amassamentos, cortes, podridões e outros fatores.

Este trabalho teve por objetivo central avaliar as perdas de diferentes variedades de manga no varejo da cidade de Petrolina (PE) e Juazeiro (BA), no ano de 2016. Já os objetivos específicos são: avaliação das perdas físicas em diferentes canais do varejo; avaliação das perdas econômicas; levantamento dos fatores de perdas nos canais do varejo; levantamento e análise de sugestões do varejo para a redução das perdas.

\section{MATERIAL E MÉTODOS}

A pesquisa de campo teve por objetivo avaliar as perdas de manga no processo de comercialização na região produtora do Vale do São Francisco. A técnica 
de pesquisa utilizada foi a entrevista altamente estruturada, com caráter exploratório, realizada durante os meses de maio a julho de 2016.

A aplicação do questionário foi realizada junto aos colaboradores dos locais pesquisados nas cidades de Petrolina (PE) e Juazeiro (BA). As entrevistas foram baseadas em um roteiro previamente elaborado e estruturado de modo a agregar as variáveis de pesquisa e identificar os gargalos existentes nesta fase importante do escoamento da produção.

Foram consideradas na pesquisa as variedades mais produzidas no Vale do São Francisco e comercializadas no varejo da cidade, sendo as variedades: Tommy Atkins, Rosa, Palmer, Espada e outras (Keit, Kent e Handen). A avaliação das perdas foi realizada mediante levantamento junto a três tipos de canais varejistas (supermercado, hortifrúti e feira livre), responsáveis pela quase totalidade dos abastecimentos de gêneros hortícolas da cidade de Petrolina (PE) e Juazeiro (BA). Foram pesquisados 10 canais de varejo (3 supermercados, 4 hortifrútis e 3 feiras livres).

Para a determinação do número de estabelecimentos de canais de varejo foi seguido o estudo de Perosa et al. (2009), que utilizaram os canais, majoritariamente, representativos na comercialização de hortifrutícolas.

Para a avaliação das perdas nos canais de comercialização explicitados anteriormente, foram utilizados critérios semelhantes a Perosa et al. (2009), porém, houve acréscimo de outros fatores. Assim, foram utilizados os seguintes dados e informações:

Preço: valor médio de venda entre os meses de maio e julho de 2016, sendo utilizado um fator de correção referente à participação do mês na média anual.

Perda física: os dados foram coletados entre os meses de maio e julho de 2016. A estimativa de perda teve como referência o mês de coleta. Assim, as porcentagens de perdas verificadas no mês de agosto foram multiplicadas pela quantidade comercializada no ano.

Características do local de comercialização: nas entrevistas feitas, foram coletados dados a respeito das condições de transporte, armazenamento, manuseio, embalagens e arrumação no local de comercialização e a frequência de compra. 


\section{RESULTADO E DISCUSSÃO}

Do total de manga comercializado no varejo do Vale do São Francisco, a variedade Tommy Atkins teve participação de 34,04\%, a Rosa 19,26\%, a Espada correspondeu a 16,13\%, a Palmer teve uma participação de $17,48 \%$, e as outras variedades como Haden, Kent e Keit corresponderam a 13,09\%. A participação da Tommy Atkins foi muito semelhante a encontrada por Perosa et al. (2009) no mercado varejista em Botucatu=(SP), quando a variedade obteve participação de $37 \%$. Já as demais variedades comercializadas não apresentaram semelhança na participação no mercado varejista.

No Vale do São Francisco há um maior equilíbrio entre a comercialização das variedades, isso ocorre pelo fato de que a região do vale possui maior oferta de produtos, tendo em 2015 uma produção de 750 mil toneladas (EXPORTAÇÕES, 2016).

Os hortifrúti são responsáveis por 53,95\% do total comercializado, seguidos pelas feiras livres com $35,71 \%$ e por último os supermercados com $10,34 \%$ da participação do total comercializado. $\mathrm{Na}$ região, o fator cultural ainda é muito presente, com uma grande tradição na comercialização de frutas nas feiras livres e hortifrútis.

Na Figura 1 está explicitado o volume de compra semanal de cada canal varejista, estratificando também o volume de cada variedade. Nos supermercados entrevistados, notou-se que houve um maior volume de compra na variedade Rosa, variedade essas que corresponde a 48,18\%. Tal variedade também se destacou na feira livre, correspondendo a 30,26\%, porém, nesse canal logístico houve um maior equilíbrio entre as variedades comercializadas. Diferentemente dos demais, o hortifrúti teve como principal variedade a Tommy Atkins, com um volume correspondente a 33,45\%. Na Figura 1 também está relatado o volume de perdas dos setores e de cada variedade. 


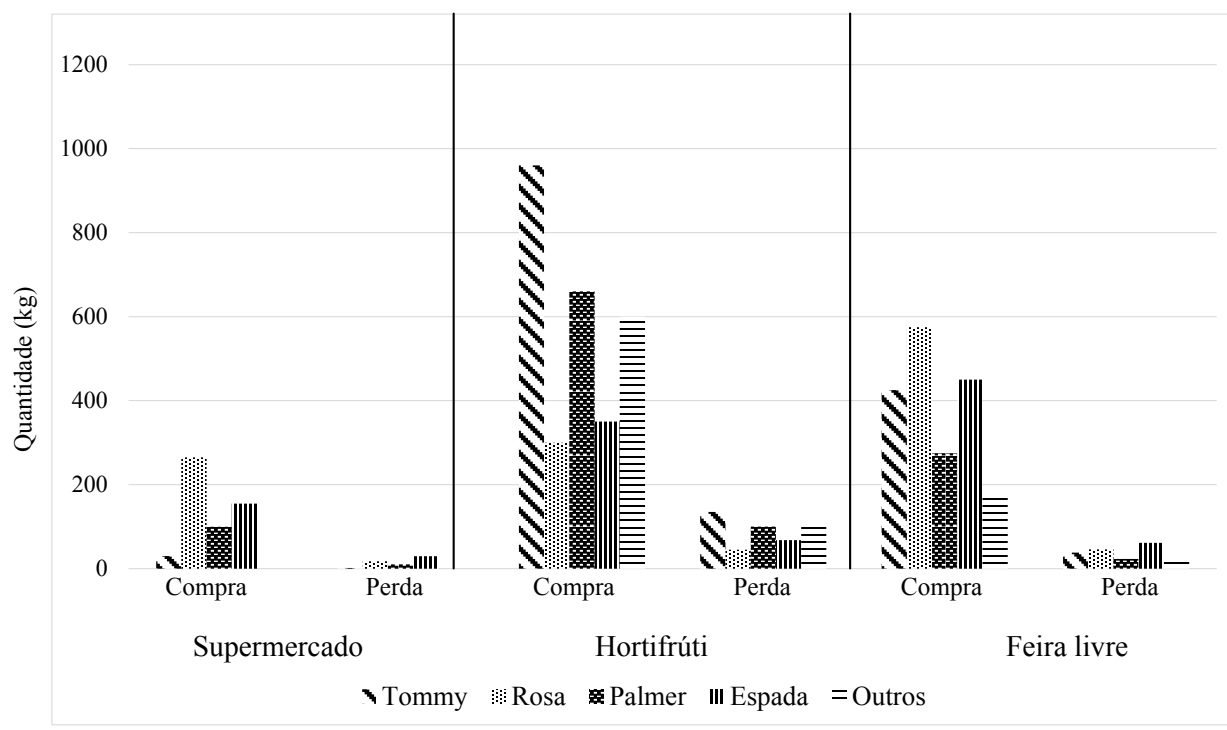

Figura 1. Volume de compra e de perda em kg por tipo de varejo Fonte: elaboração dos autores.

O percentual de perdas, por canal varejista, mostra-se indicadores de menor perdas nas feiras livres $(9,78 \%)$, seguidos por supermercados $(10,70 \%)$ e hortifrútis $(15,88 \%)$. Os resultados obtidos são semelhantes aos descritos por Perosa et al. (2009) na comercialização da manga em Botucatu (SP). No estudo desenvolvido em Botucatu foi identificado o canal varejista supermercados como o que apresentou menor perda (10,5\%), seguidos das feiras livres $(13,3 \%)$ e das quitandas/sacolóes (14,5\%). Silva et al. (2003) afirmam que a exposição em hortifrútis é feita em espaços relativamente amplos, com grande variedade de produtos, dificultando o controle da manipulação dos clientes. Já o baixo índice de perda pelos feirantes pode estar relacionado ao tipo de fornecedor, que em sua grande maioria são agricultores. A eliminação do canal atacadista da cadeia de comercialização faz com que haja um elemento a menos na cadeia, reduzindo o número de manuseio e transporte que o produto sofre, que, de acordo com Choudhury e Costa (2004), são umas das principais causas de perda na manga. 
Tabela 1. Volume comprado, percentual e quantidade de perdas e preço da manga no Vale do São Francisco

\begin{tabular}{c|ccccc}
\hline Produtos & $\begin{array}{c}\text { Volume } \\
\text { comprado/ } \\
\text { semana (kg) }\end{array}$ & $\begin{array}{c}\text { Perda } \\
\text { semanal (\%) }\end{array}$ & $\begin{array}{c}\text { Perda média } \\
\text { semanal } \\
\mathbf{( k g )}\end{array}$ & $\begin{array}{c}\text { Preço médio } \\
\mathbf{( \$ )}\end{array}$ & $\begin{array}{c}\text { Perda média } \\
\text { semanal } \mathbf{( \$ )}\end{array}$ \\
\hline Tommy & 2015 & 14 & 277,08 & 2,45 & 677,81 \\
Rosa & 1140 & 7 & 83,88 & 4,35 & 364,65 \\
Palmer & 1035 & 12 & 124,63 & 3,00 & 373,74 \\
Espada & 955 & 17 & 157,93 & 3,21 & 506,78 \\
Outros & 775 & 14 & 111,82 & 3,25 & 363,74 \\
\hline
\end{tabular}

Fonte: elaboração dos autores.

O valor total das perdas estimadas por cada variedade é evidenciado na Tabela 1 , com uma estimativa para valor total de perdas sendo de $\mathrm{R} \$ 2.286,71$ semanais, soma dos valores de cada variedade, referindo-se aos canais varejistas explicitados na pesquisa. Tal estimativa demonstra o quão as perdas impactam, fazendo uma avaliação para um universo de tempo anual, o volume monetário perdido com a comercialização da manga nesses canais varejistas investigados podem corresponder a aproximadamente $\mathrm{R} \$ 120$ mil. Sendo que na região do vale existem diversos locais de comercialização de manga que não foram investigados, essas perdas podem chegar a números bem mais expressivos.

Avaliando os fornecedores dos canais varejistas investigados, a Figura 2 ilustra os principais, mostrando que o Mercado do Produtor - BA possui a maior participação. Segundo Machado e Carvalho (2016), o mercado localizado na cidade de Juazeiro, no Estado da Bahia, foi criado como entreposto comercial para produtos que fossem cultivados ou não na região do Vale do São Francisco.

Outro fornecedor que se destacou foi o agricultor, alguns canais de comercialização já adquiriam seus produtos diretamente das fazendas de cultivo, tentando assim barganhar melhores preços e produtos de melhor qualidade. Freire, Marinho e Walter (2012) relatam que o pequeno produtor vende a manga para os intermediários, que fornecem para o varejo, chegando até o consumidor final. No caso dos grandes produtores, grande parte de sua produção é distribuída diretamente com redes de comercialização. 
A pequena parcela de 1\% destacada na Figura 2 retrata aqueles fornecedores que não possuem uma frequência de fornecimento de produtos para os canais varejistas; normalmente, eles aparecem com os produtos em caminhonetes tentando vender suas mangas para o varejista. Esse tipo de fornecedor foi identificado no setor de hortifrúti e nas feiras livres, mercados que possuem maior informalidade.

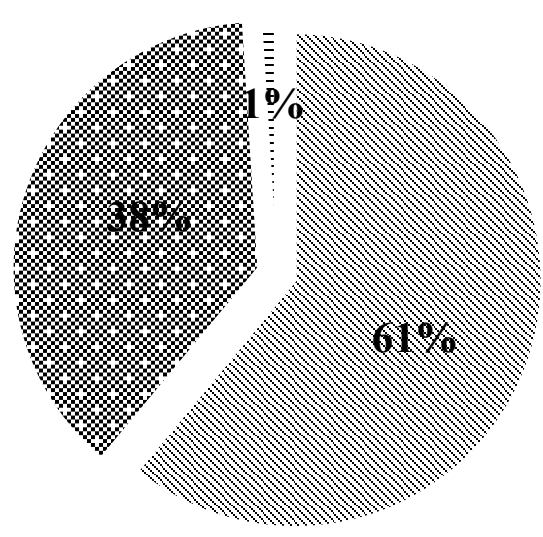

« Mercado do Produtor - Juazeiro-BA $\approx$ Agricultor $=$ Outro tipo de fornecedor

Figura 2. Origem dos Produtos

Fonte: elaboração dos autores.

A utilização de embalagens adequadas é crucial para a manutenção da qualidade das mangas. Foi identificada a prevalência da utilização de caixas plásticas, conhecida como contentores, como embalagem única utilizada para transporte dos frutos até o local de comercialização.

De acordo com Lorenzi et al. (2014), a caixa plástica tem a vantagem de ser retornável e de também possuir melhores características quando se trata de higienização. No estudo de Perosa et al. (2009) houve a identificação da utilização de outros tipos de embalagens como a madeira e o papelão. Castro e Julioti (2009) relatam que em 12 de novembro de 2002 foi instituída pelo Instituto Nacional de Metrologia (INMETRO), pela Agência Nacional de Vigilância Sanitária (ANVISA) e 
pela Secretaria de Apoio Rural e Cooperativismo (SARC), a Instrução Normativa ${ }^{0}$ 09, regulamentando o acondicionamento, o manuseio dos produtos hortifrutícolas in natura em embalagens próprias para a comercialização, visando a proteção, conservação e integridade dos mesmos. Sua principal exigência foi a de que as embalagens fossem retornáveis.

Baseado na higienização das embalagens utilizadas para o transporte da manga, realizou-se o questionamento a respeito da frequência em que as embalagens eram higienizadas. Na Figura 3 informa-se que o setor de supermercados possui a melhor média de frequência de limpeza das embalagens, cerca de 11 vezes por mês. Houve casos em que o comerciante fazia essa higienização diariamente, já outros faziam a cada 15 dias, ocasionando uma grande variabilidade dos dados coletados. Em nenhum dos locais investigados houve o uso exclusivo de embalagens para as variedades de manga investigadas, havendo uma rotatividade dos contentores utilizados.

As normas disponíveis no Ministério da Agricultura, Pecuária e Abastecimento - MAPA, "Instrução Normativa Conjunta SARC/ANVISA/INMETRO n ${ }^{\circ} 009$ ", não relatam a frequência mínima em que as embalagens devem ser higienizadas, mas Cenci (2006) afirma que as embalagens devem ser sempre desinfetadas antes do uso a fim de minimizar a contaminação por microrganismos.

Feira-livre

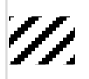

Hortifrúti

Supermercado

0

2

4

6

8

10

12

Dias

Supermercado Hortifrúti Feira-livre

Figura 3. Frequência da limpeza das embalagens por mês Fonte: elaboração dos autores. 
A Tabela 2 mostra as principais causas de perdas segundo a percepção dos varejistas. Dos canais investigados, houve uma maior concentração dos causadores de perdas nos elementos: transporte, baixa qualidade da fruta, manuseio dos clientes, fruta muito madura e outros. Cada local de comercialização apresentou suas particularidades.

Não houve uma igualdade entre todos os canais de comercialização para a principal causa de perdas, mas houve a hegemonia da manipulação do cliente em 2 canais dos 3 investigados: nas feiras livres e nos supermercados. Esse destaque do fator 'manipulação do cliente' também é encontrado na pesquisa de Perosa et al. (2009), os dados mostraram que essa causa é destaque de perdas no setor de supermercados (27,3\%), quitandas/sacolões (26,3\%) e em feiras livres (25\%). Nessa pesquisa executada no Vale do São Francisco, identificou-se o percentual de 33,33\% nos supermercados, 17,24\% nos hortifrútis e de 46,43\% nas feiras livres.

Tabela 2. Principais causas de perdas de manga, de acordo com os responsáveis pelo canal varejista na região do Vale do São Francisco

\begin{tabular}{r|ccc}
\hline \multicolumn{1}{c|}{ Principais causas } & Supermercado & Hortifrúti & Feira Livre \\
\hline (1) forma de exposição da fruta & $0,00 \%$ & $0,00 \%$ & $0,00 \%$ \\
(2) embalagens & $0,00 \%$ & $0,00 \%$ & $0,00 \%$ \\
(3) excedente de oferta & $0,00 \%$ & $0,00 \%$ & $0,00 \%$ \\
(5) baixa qualidade da fruta & $16,67 \%$ & $0,00 \%$ & $35,71 \%$ \\
(6) manuseio dos clientes & $33,33 \%$ & $17,24 \%$ & $46,43 \%$ \\
(7) fruta muito madura & $16,67 \%$ & $58,62 \%$ & $0,00 \%$ \\
$(8)$ outros & $25,00 \%$ & $0,00 \%$ & $0,00 \%$ \\
\hline
\end{tabular}

Fonte: Elaboração dos autores.

Já no setor de hortifrúti, foi identificado que fruta muito madura é o principal causador de perdas $(58,62 \%)$, problema também encontrado nos supermercados investigados (16,67\%). De acordo com Chitarra e Chitarra (2006) frutas in natura são compostas por tecidos vivos sujeitos a modificações contínuas 
após a colheita, uma delas é o amadurecimento do fruto. Haja vista que os hortifrútis apresentam o maior volume de compra semanal, é nítido que se não houver um local adequado para a armazenagem, a atividade metabólica dos frutos se acelera e o amadurecimento se dá mais rápido, prejudicando assim a qualidade dos produtos. Cenci (2011) corrobora afirmando que a taxa de respiração dos tecidos vegetais aumenta exponencialmente com o aumento da temperatura, deficiências no controle de temperatura nas diferentes etapas como recepção, estocagem, processamento, armazenamento, transporte, distribuição e comercialização do produto têm repercutido negativamente na segurança, qualidade e vida útil das frutas.

A fim de afirmar que as condições de armazenagem influenciam, Calbo et al. (2007) consideram que a elevação da temperatura causa um aumento exponencial da taxa de respiração e também causa redução exponencial da vida útil das frutas e hortaliças compatível com os efeitos da temperatura sobre a respiração na maioria dos produtos vegetais.

Por outro lado, a Tabela 3 mostra as principais causas por variedade de manga investigada. De acordo com Costa e Santos (2004), cada variedade apresenta características próprias. A manga Espada, variedade brasileira mais antiga e comum, o fruto é verde intenso ou amarelo esverdeado, de tamanho médio (em torno de $300 \mathrm{~g}$ ), com casca lisa e espessa. A polpa tem muita fibra e coloração amarelada. Possui sabor de regular para bom (em torno de $18^{\circ}$ Brix) e tem lugar de destaque no mercado interno. Já a Rosa é um fruto que varia de amarelo para rosa-vermelho, peso médio em torno de $350 \mathrm{~g}$. A casca é espessa e lisa; a polpa é amarelo ouro e moderadamente suculenta, fibrosa e de bom sabor (21,8 Brix). Já os frutos possuem casca roxa quando "de vez" e vermelhos quando maduros. A polpa é amarelada, firme, bom sabor (21,6 Brix), com pouca ou nenhuma fibra. Relação polpa/fruto é de $72 \%$, teor médio de fibras e casca fina.

Lima Neto, Santos e Costa (2010) afirmam que a variedade Tommy Atkins apresenta elevada produtividade, regularidade na produção e uma considerável resistência aos impactos mecânicos, podendo ser facilmente transportada por grandes distâncias. Outra característica é a resistência à deterioração após a colheita, sendo, portanto, muito menos perecível que as demais variedades cultivadas para os mercados internacionais. 
Tabela 3. Principais causas de perdas de manga, de acordo com variedade do fruto

\begin{tabular}{rccccc}
\hline \multicolumn{1}{c}{ Principais causas } & Tommy & Rosa & Palmer & Espada & Outros \\
\hline $\begin{array}{r}\text { (1) forma de exposição } \\
\text { da fruta }\end{array}$ & $0,00 \%$ & $0,00 \%$ & $0,00 \%$ & $0,00 \%$ & $0,00 \%$ \\
(2) embalagens & $0,00 \%$ & $0,00 \%$ & $0,00 \%$ & $0,00 \%$ & $0,00 \%$ \\
(3) excedente de oferta & $0,00 \%$ & $0,00 \%$ & $0,00 \%$ & $0,00 \%$ & $0,00 \%$ \\
(4) transporte & $15,38 \%$ & $14,29 \%$ & $14,29 \%$ & $12,50 \%$ & $16,67 \%$ \\
(5) baixa qualidade da fruta & $23,08 \%$ & $21,43 \%$ & $21,43 \%$ & $25,00 \%$ & $16,67 \%$ \\
(6) manuseio dos clientes & $30,77 \%$ & $35,71 \%$ & $28,57 \%$ & $25,00 \%$ & $33,33 \%$ \\
(7) fruta muito madura & $30,77 \%$ & $21,43 \%$ & $28,57 \%$ & $31,25 \%$ & $33,33 \%$ \\
(8) outros & $0,00 \%$ & $7,14 \%$ & $7,14 \%$ & $6,25 \%$ & $0,00 \%$ \\
\hline
\end{tabular}

Fonte: elaboração dos autores.

Devido à grande necessidade da variedade Tommy Atkins para a exportação, a sua produção é bem superior às demais, fazendo com que o que não é direcionado para o mercado exterior seja comercializado pelo Brasil. Essa variedade apresentou um índice de perda moderado, em torno de $14 \%$, mostrando que as características descritas anteriormente possam ter influenciado nesse número. No mais, os elementos causadores se assemelharam muito aos investigados por tipo de varejista, mostrando quase que total igualdade.

\section{CONSIDERAÇÕES FINAIS}

Com uma correspondência em 2015 de $84 \%$ da manga exportada, o Vale do São Francisco possui grande significância na produção e comercialização dessa fruta.

O hortifrúti apresentou o maior volume de compra semanal, apresentando também o maior índice de perdas em percentual. Indica-se que o canal varejista fracione suas compras, já que os mesmos não possuem um local adequado para a conservação do fruto por um maior tempo. 
As principais causas de perdas correspondem ao nível elevado de maturação do fruto, com índice quantificado de $58,62 \%$, problema que poderia ser reduzido com a melhoria das condições de armazenagem e exposição do fruto.

Já no supermercado e na feira livre, com percentual de perda de 33,33\% e 46,43\%, respectivamente, sugere-se a realização de maiores investimentos na conscientização dos clientes, a fim de informá-los que a manipulação excessiva influencia diretamente na qualidade do fruto.

Sendo assim, considera-se que os canais mais tradicionais da região do Vale do São Francisco necessitam desenvolver melhor sua distribuição de manga para os clientes, a fim de reduzir as perdas.

\section{REFERÊNCIAS}

ANUÁRIO BRASILEIRO DE FRUICULTURA: Brazilian Fruit Yearbook. Santa Cruz do Sul: Gazeta Santa Cruz, 2016.

BANCO DE ALIMENTOS. Desperdício de Alimentos: Só no Brasil, 26,3 milhões de toneladas de alimentos têm o lixo como destino. Disponível em: $<$ http://www. bancodealimentos.org.br/conheca-banco-de-alimentos/desperdicio-de-alimentosbrasil-e-mundo/> . Acesso em: 10 jun. 2016.

CALBO, A. G.; MORETTI, C. L.; HENZ, G. H. Respiração de Frutas e Hortaliças. Brasília: EMBRAPA-CTAA, 2007. (EMBRAPA-CTAA. Comunicado, 46).

CASTRO NETO, M. T. de Q.; CUNHA, G. A. P. da. Introdução. In: MATOS, A. P. de (Org.). Manga Produção: aspectos técnicos. Brasília: Embrapa Comunicação Para Transferência de Tecnologia, 2000.

CASTRO, R. de; JULIOTI, P. S. Embalagens de Produtos Hortifrutícolas "In Natura": descrição de um modelo logístico reverso nas centrais de abastecimento (CEASAS). In: ENCONTRO NACIONAL DE ENGENHARIA DE PRODUÇÃO, 29, 2009, Salvador. Anais... . Salvador: ABEPRO, 2009. p. 1-14. 
CENCI, S. A. Boas Práticas de Pós-colheita de Frutas e Hortaliças na Agricultura Familiar. In: NASCIMENTO NETO, F. (Org.). Recomendações Básicas para a Aplicação das Boas Práticas Agropecuárias e de Fabricação na Agricultura Familiar. Brasília: Embrapa Informação Tecnológica, 2006, p. 67-80.

CENCI, S. A. (Ed.). Processamento mínimo de frutas e hortaliças: Tecnologia, qualidade e sistemas de embalagem. $21^{\mathrm{a}}$ ed. Rio de Janeiro: Embrapa Agroindústria de Alimentos, 2011. 144p.

CHITARRA, M. I. F.; CHITARRA, A. B. Pós-colheita de frutas e hortaliças: glossário. Lavras: UFLA, 2006. 256p.

CHOUDHURY, M. M.; COSTA, T. S. da. Perdas na Cadeia de Comercialização da Manga. Petrolina: Embrapa Semiárido, 2004. 44 p. (Embrapa Semiárido, Documentos, 186).

COSTA, J. G. da; SANTOS, C. A. F. Principais cultivares de manga para as condições do Vale do São Francisco. 2004. Disponível em: < https://sistemasdeproducao.cnptia. embrapa.br/FontesHTML/Manga/CultivodaMangueira/cultivares.htm\# espada $>$. Acesso em: 07 ago. 2016.

EXPORTAÇÕES de manga do Vale do São Francisco crescem 20\%. 2016. Disponível em: $<$ http://jconline.ne10.uol.com.br/canal/economia/pernambuco/noticia/2016/05/27/ exportacoes-de-manga-do-vale-do-sao-francisco-crescem-20_porcento--237621. php>. Acesso em: 07 ago. 2016.

FREIRES, F. G. M.; MARINHO, S. V.; WALTER, F. Anais de distribuição da manga e da uva de mesa produzidas no Vale do São Francisco: uma análise comparativa. In: CONGRESSO BRASILEIRO DE ENGENHARIA DE PRODUÇÃO, 31. Anais... Bento Gonçalves: Abepro, 2012.

IPEA. Desperdício - Custo para todos: alimentos apodrecem enquanto milhões de pessoas passam fome. 2009. Disponível em: < http://www.ipea.gov.br/desafios/index. php?option $=$ com_content $\&$ view $=$ article $\& i d=1256$ : catid $=28 \&$ Itemid $=23>$. Acesso em: 07 ago. 2016. 
LIMA NETO, F. P.; SANTOS, C. A. F.; COSTA, J. G. da. Cultivo da Mangueira. 2010. Disponível em: <https://sistemasdeproducao.cnptia.embrapa.br/FontesHTML/ Manga/CultivodaMangueira_2ed/cultivares.htm > . Acesso em: 07 ago. 2016.

LORENZI, C. O. et al. Embalagens de HF no Brasil. Hortifruti Brasil, n. 137, p. 8-21, ago. 2014.

MACHADO, W. R. B.; CARVALHO, J. L. M. de. Causas de perdas na comercialização: o caso da laranja no Mercado do Produtor em Juazeiro (BA). In: SIMPÓSIO DE ENGENHARIA DE PRODUÇÃO. Anais... RECIFE: FBV, 2016.

PEROSA, J. M. Y. et al. Avaliação das perdas de manga (Mangifera indica L.) no mercado varejista da cidade de Botucatu-SP. Revista Brasileira de Fruticultura, Jaboticabal, v. 31, n. 3, p. 732-738, set. 2009.

PINTO, C. A. de Q.; MATOS, A. P. de; CUNHA, G. A. P. da. Variedades (Cultivares). In: MATOS, A. P. de (Org.). Manga Produção: aspectos técnicos. Brasília: Embrapa Comunicação Para Transferência de Tecnologia, 2000.

SEBRAE. Mercado de Fruticultura: Panorama do setor no Brasil. 2015. Disponível em: < http://www.sebraemercados.com.br/wp-content/uploads/2015/11/Panoramado-mercado-de-fruticultura-no-Brasil.pdf> . Acesso em: 07 ago. 2016.

TOFANELLI, M. B. D. et al. Perdas de frutas frescas no comércio varejista de MineirosGO: um estudo de caso. Revista Brasileira de Fruticultura, Jaboticabal, v. 29, n. 3, p. 513-517, 2007.

TRENTO, E. J.; SEPULCRI, O.; MORIMOTO, F. Comercialização de Frutas, Legumes e Verduras. Curitiba: Instituto Emater, 2011. 40p. Disponível em: < http://www. asbraer.org.br/arquivos/bibl/79-com.pdf> . Acesso em: 28 jun. 2016.

VILELA, N. J.; LANA, M. M.; MAKISHIMA, N. O peso da perda de alimentos para a sociedade: o caso das hortaliças. Horticultura Brasileira, Brasília, v. 21, n. 2, p. 141-143, abr./jun. 2003.

Recebido em: 27 setembro de 2016 Aceito em: 01 de março de 2017 